\title{
ARTICLES, PERSPECTIVES, AND TPDP
}

\author{
LARS VILHUBER
}

Managing Editor, Journal of Privacy and Confidentiality, and Cornell University e-mail address: managing-editor@journalprivacyconfidentiality.org

The present issue provides a diverse selection of articles. We introduced a new type of article, "Perspectives," in the previous issue, and continue with two such articles in the current issue, both drawn again from presentations made at the October 2020 Canadian Research Data Centre Network (CRDCN) conference. ${ }^{1}$ Roxane Silberman gives an overview of secure access to confidential data in France, with a glimpse of what else is going on in Europe, while Michael Harvey discusses the concept of secure research data centers from the perspective of a (Canadian) regulator. ${ }^{2}$

We also have a new article on the topic of "Privacy Challenges," edited by Daniel Kifer. Tianhao Wang, Ninghui Li, and Zhikun Zhang describe their "Experiences in [two] NIST Differential Privacy Data Synthesis Challenges." Two additional articles, from McKenna, Miklau, and Sheldon (winners of the 2018 NIST DP competition) and from Bao, Xiao, Zhao, Zhang, and Ding, will be published in the next issue.

The 6th Workshop on Theory and Practice of Differential Privacy (TPDP 2020) was held virtually on 13 November 2020 as part of the ACM Conference on Computer Security (CCS) 2020. This issue presents the first of several journal versions of contributions to that workshop, from Yuval Dagan and Vitaly Feldman, on "Interaction is Necessary for Distributed Learning with Privacy or Communication Constraint." Additional manuscripts are forthcoming in the next issue. TPDP 2021 took place (virtually again) on 23 July 2021. Selected papers from the workshop will be invited to submit a full version of their work for publication in this journal. Rachel Cummings edited the TPDP 2020 papers, Gautam Kamath will be editing the TPDP 2021 papers.

Finally, Cynthia Dwork, Weijing Su, and Li Zhang present work on "Differentially private false discovery rate control." ${ }^{3}$

Key words and phrases: perspectives, privacy, challenge, TPDP.

${ }^{1}$ See https://www.crdcn20.ca/ for more information.

${ }^{2}$ Previous "perspectives" include Ron Jarmin's reflections on the US network, and Felix Ritchie on the topic of "Privacy and Microdata Access: Two Worlds Colliding?"

${ }^{3}$ As per the Journal's policies, Dwork, even though Editor-in-Chief of this journal, did not participate in the editorial process, and all aspects of the editorial workflow were blinded (not accessible) to her.

$$
\begin{array}{ll}
\text { Privacy } & \text { www.journalprivacyconfidentiality.org } \\
\text { COnfidentiality } & \text { DOl:10.29012/jpc.801 }
\end{array}
$$

(c) L. Vilhuber

(oc) EY-NC-ND Creative Commons (CC BY-NC-ND 4.0)

This work is licensed under the Creative Commons License Attribution-NonCommercialNoDerivatives 4.0 International (CC BY-NC-ND 4.0). To view a copy of this license, visit https://creativecommons .org/licenses/by-nc-nd/4.0/ or send a letter to Creative Commons, 171 Second St, Suite 300, San Francisco, CA 94105, USA, or Eisenacher Strasse 2 , 10777 Berlin, Germany 